\title{
Unified Model for Learning Style Recommendation
}

\author{
Unhawa Ninrutsirikun*, Debajyoti Pal, Chonlameth Arpnikanondt \\ and Bunthit Watanapa
}

School of Information Technology, King Mongkut's University of Technology

Thonburi Bangkok, Thailand

E-mail:unhawa@gmail.com,unhawa@sit.kmutt.ac.th;

debajyoti.pal@sit.kmutt.ac.th; chonlameth@sit.kmutt.ac.th; bunthit@sit.kmutt.ac.th ${ }^{*}$ Corresponding Author

Received 25 August 2020; Accepted 17 February 2021;

Publication 12 July 2021

\begin{abstract}
Studying computer programming requires not only an understanding of theories and concepts but also coding adeptness. Success in studying or conducting such a course is definitely a challenge. This paper proposes a systematic learning style recommendation. The model is designed to evaluate students' attributes and ongoing or formative learning outcomes for suggesting the effective style-fit strategy that facilitates learners to enhance their learning performances in terms of knowledge and skill. A two-stage association analysis was designed and conducted on a dataset collected from IT major students who enrolled in the Introduction to Computer Programming course. The first stage of association rules is to analyze and discover important relationships amongst learning styles, students' attribute, and learning performance. The second stage of moderation analysis is then applied to probe the moderation effect of the different learning preferences on the relationship between student attributes and learning achievement. Experiments expose many insights, for example, mathematics and logical thinking are powerful assets of success in computer programming study. Association rules can effectively identify associations of learning styles and
\end{abstract}

Journal of Web Engineering, Vol. 20_5, 1425-1464.

doi: 10.13052/jwe1540-9589.2058

(C) 2021 River Publishers 
the learning performance in terms of knowledge or skills. By moderation analysis, students in the "Excellent" cluster have a broad learning style than other students. Two types of significant moderators, the universal and specific, exemplify how lecturers can flexibly post style-fit teaching strategies for a class-wide and specific group, respectively.

Keywords: Association evaluation, association rules, guideline, learning styles, moderation analysis, style-fit strategy.

\section{Introduction}

The introduction to computer programming course is an important fundamental subject in computer study and related fields, e.g., computer science (CS) and information technology (IT). The knowledge and skills obtained from this course underlie most of the following main courses and clusters of elective subjects in the CS/IT oriented programs. However, this course is one of the toughest for both teaching and learning, as evident from the current failure rates [1-4].

To increase student success rates in learning to program, researchers and educators have improved the teaching and learning process with three main methods [5]. Current works can broadly be classified into various categories such as (1) prediction of student's learning performance, (2) clustering the students according to their learning performance [6] or profiles [7], and (3) the association rule mining for revealing the insight information to support the stakeholder in decision making [8]. However, most of their efforts are fragmented, separate, and discontinuous, thereby needing a cohesive treatment to track the student's learning progress and recommend style-fit strategies. There is a need for developing a comprehensive conceptual framework that integrates the aspect of improving the students' learning performance and gaining the essential skills to apply with the related work. Forming a unified framework for dynamically suggesting a style-fit learning strategy according to the sensed student's learning preference and learning progress for continually improving student's learning performance is a challenge.

The aim of this research is to investigate the association evaluation process and the systematic interaction amongst the elements in the proposed unified system for achieving effective recommendation of style-fit learning strategies. The intensive association rules mining (ARM) algorithm is adopted to reveal the direct association among students' posterior profiles, learning styles, and level of learning performance. Likewise, the moderation 
analysis is adopted to reveal the moderation effect of students' learning style on the posterior profiles and the learning performance.

The remainder of the paper is organized as follows. Section 2 discusses the related work and background information. Section 3 introduces the proposed framework, the modular architecture of the unified system, and the adopted methodology to control the synergistic working of the core modules. Section 4 describes the experimental design. Section 5 presents the experimental results. Section 6 illustrates insightful discussion. Section 7 summarizes the study, pointing out the limitation and future research direction.

\section{Related Works}

This section provides background information and motivation for this work by conducting a state-of-the-art literature review. The literature review is presented in three distinct subsections. The first subsection examines the potential features of an individual student and the optimization factors for association evaluation analysis. The second subsection discusses the learning performance measurement, while the last one discusses the association rule evaluation.

\subsection{Potential Factors for Adaptive Learning Systems}

The adaptive learning system usually consists of two essential modules: performance prediction and adaptive evaluation $[9,10]$. Personal information (or student profiles) has been considered the important determinants for predicting students' performance, in the extant literature. However, most of them are static determinants. For adaptive system, learning styles or strategies have been considered an important factor for redirecting or enhancing the learning result [11].

\subsubsection{Determinants for predicting study performance}

Most of the studies in the education domain, including computer education, have consistently indicated that students' cognitive ability is correlated strongly with the academic achievement [12]. The academic background (AB) is the traditional cognitive factor recognized as a powerful predictor $[13,14]$. It is observed in many studies that the ability in mathematics, science [15], and foreign language fluency (for a nonspeaking English country) [16] is a related factor to predict a student's success in a computer 
programming course. Multiple intelligence (MI), which is a form of human intellectual competencies, is another cognitive ability that was utilized as a predictor of students learning performance $[14,17]$. Results of the previous studies showed that the word smart (linguistic intelligence) and numberreasoning smart (logical-mathematical intelligence) represent the scholarly intelligence $[14,17]$. In the areas of mathematics and computer education, number-reasoning smart and picture smart (spatial intelligence) were reported as the most important intelligence for studying computer programming $[14,17,18]$. Moreover, it was confirmed that adopting the MI as a copredictor together with the traditional factors can enhance the prediction model's performance [14]. Recently, researchers have designed a set of learning activities based on the MI approach [19] for improving the performance in computer programming of first-year undergraduate students.

On the other hand, many pieces of research in computer education examined the non-cognitive skills that contribute to the success of computer programming studies [20-22]. The Big Five model is one of the favorite models used in many studies to comprehend the personality of an individual based on a set of predefined dimensions [23]. This model, found to have a relationship with the academic performance [24-26], comprises openness, conscientiousness, extraversion, agreeableness, and neuroticism. Conscientiousness describes a socially prescribed impulse control. It is the strongest element with academic success in higher education [24], whereas neuroticism (the characteristics of anxiety and unstable emotions) is reported in the opposite [26]. Openness as well as extraversion have only a moderate association with learning performance [21]. Moreover, neuroticism is the only element of this model that negatively affects with the programming aptitudes [21].

The significant predictors are traditionally composed of comprehensive input variables. Unluckily, the increasing number of predictive factors leads to the probable multicollinearity problem [27]. Having an awareness of this concern, the feature extraction was adopted for finding the optimal factors [28]. Previous research of the authors [20] utilized the specific process for converting the original input into new dimensions. The obtained results are the effective optimal input factors and the insightful information of students in each performance level can be interpretable.

\subsubsection{Learning style in adaptive learning system}

Every student has a different $\mathrm{AB}$ as well as learning strategies. Therefore, the one-size-fits-all learning environment is usually not a good strategy for being 
panacea-like deployment. An adaptive learning system might be considered as an approach to monitor and recommend some changes to the teacher or learner in a dynamic way that enables the classroom to achieve learning outcomes $[29,30]$. One of the important modules of the adaptive learning system is the adaptive engine, which recommends the appropriate learning material and method. The literature reveals that various factors, such as students' performance [11], students' learning behavior [31], and students' learning preference, have been used as the adaptive indicators [11]. Among those variables, the learning style is one of the most widely adopted adaptive indicators $[11,32]$. It is reported to have a significant effect on the learning process [30]. The proper assortment of the learning environment and learning style may enhance learning achievement [33].

A student's learning style refers to how an individual perceives, processes, understands, and retains information [34]. The style-fit learning environment and learning material support learners to get effective learning and progress [35]. Consequently, various learning style models have been presented by researchers such as Honey and Mumford [23], Kolb [36], Mayer and Myers [37], Dunn [38], and Felder and Silverman [39]. Among these learning styles, this study adopted the Felder and Silverman learning style model (FSLSM) [40], constructed by expert in educational psychology and engineering education was adopted in this study. The FSLSM is the widely used model for science and engineering education [32, 41, 42]. This model defined the following four dimensions of learning preference [35]:

(1) Process - How does the student prefer to process information? Active or reflective.

(2) Perception - What type of information does the student preferentially perceive? Sensory or intuitive.

(3) Through which sensory channel is external information most effectively perceived? Visual or verbal.

(4) Understand: How does the student progress toward understanding? Sequential or global.

Several computer education research exposed the relationship between students' learning styles and learning performance that reflective and verbal students tend to achieve in computer programming courses [41-43]. The study of [44] reported that reflective, intuitive, verbal, and global students tend to succeed on programming exam, while reflective, sensing, verbal, and sequence students typically perform the best in the class. Those studies show that learning styles correlate with computer programming performance and 
some learning styles are more suitable for learning computer programming subject [44]. The interesting insights from those analyses have been utilized in the adaptive engine in various ways $[45,46]$, such as providing the adaptive learning contexts, adaptive learning resource format, and adaptive teaching strategies.

Literature in computer education always used correlation analysis and other data mining approaches to analyze and retrieve valuable information. Simultaneously, the interaction effect analysis is another powerful approach that examines the effect of the third variable on the relationship between two variables. However, the interaction effect (or moderation) analysis has not been done in the present research context.

\subsection{Learning Performance Measuring}

The appropriate performance measuring scheme is supposed to guide the stakeholders, especially students and lecturers, to understand the level of achievement according to the study's objective. On the other hand, predictive performance based on pre- or formative-testing could help forewarn potential problems, e.g., at-risk students or suggest reorganization of the learning process based on the known relationship between signified predictors and the presumed learning performance [47].

Normally, the total score is the summative evaluation of a student's performance, accumulated from assignments, tests, and course participation. In the causal and prediction systems, most of the literature used the total score or grade to represent the students' performance [48, 49]. However, the course grade cannot indicate integral parts of ability [50]. Bergersen et al. [51] pointed out that segregating the learning performance into knowledge and skills would make it easy to extract the students' strengths and/or weaknesses. However, some researchers, including Campbell et al. [52] and Bergersen et al. [51], extended performance in pragmatic subjects into three dimensions of improvement: knowledge, skills, and attitude (or motivation). The motivation was reported as a reinforcing factor for performance [52]. Being aware of improvement or deficiency in progress, students should be guided to the link with the methods to achieve greater success [53].

\subsection{Association Analysis}

The ARM is the process of discovering the interesting relationship between the co-occurrence of items in the dataset $[54,55]$. The ARM has been 
applied in various education research lines, e.g., improving the course curriculum [56], the quality of the learning management system service [57], and teaching method and learning environment [58, 59]. Moreover, ARM has been applied to online learning systems for various tasks, e.g., providing feedback or recommendations for the students and instructors [60], to recommend student's learning activities [61] and learning material [62].

Applying the association rules analysis with the online learning systems was reported to have some drawbacks, e.g., discovering too many rules or poor understandable rules [63]. The study from Merceron and Yacef [64] reported that size of the sample dataset has a predominant effect on the results (number of the interesting rules). To identify the interesting rules of the small sample size, two adequate thresholds (support and confidence) and extra threshold (cosine or lift) are needed. While the support and confidence values reflect the basis and strength of the analysis, the lift value measures the probabilistic sufficiency of the association. In general, the potential rule for predicting the consequence in future data should have the lift value greater than 1 [64].

\subsection{Moderation Analysis}

The moderation analysis is the investigation process for the particular association, which is presumed that the causal variable $X$ on the outcome variable $Y$ is moderated by another variable in the model ( $X$ 's effect depends on the other variable) [65]. The meaning of this association was interpreted as the different values (in size or sign) of the moderator cause the antecedent $(X)$ effect on consequence $(Y)$ differently. When the interaction effect is significant, the meaning of the association could be interpreted as enhancing or buffering. The enhancing effect occurs when the value of the moderator increases, thereby magnifying the effect of the antecedent on the outcome. On the contrary, the buffering occurs when the value of the moderator increases, but the effect of the antecedent on the outcome decreases. While antagonistic is the interaction in terms of the sign when the value of the moderator increases, the effect of the antecedent on the outcome is reversed.

The original research of moderation analysis had been proposed in personality psychology and widely used in behavioral science [66, 67]. Most researches performed moderation analysis to consider the interaction effect between a dependent and independent variable such that the relationship between these may vary across different levels of the moderating variable [68]. 
Various researches in the area of computer and education have adopted the idea of moderation analysis in the education setting, such as the gamification as a moderator on student learning through the testing effect [69], students' general academic achievement as a moderator of the relationship between social networking use and learning performance [68], and learners' prior knowledge and task difficulty have been identified as important moderators in the relation between feedback and learning [70-72]. Nevertheless, there is still lack of studies in an education setting using the students' learning style as a moderator especially in the adaptive learning framework research topic.

\subsection{Learning Recommendation}

One of the key elements of the adaptive learning framework is the adaptive engine or the recommendation module. This module is an algorithm that integrates information derived from the preceding models in order to select appropriate learning content to present to the students [73]. This module is the core process of the adaptive learning systems and it is very important in generating automatic recommendations [74]. Most researches selected to analyze student's learning preferences and/or habits because these factors enable changeability [75]. Another reason is that the lecturers/educators can get information about how learners used to learn, and deep understanding might help prepare learning material and design the teaching and learning method [30, 76]. The data mining algorithm based on the a priori technique is adopted to discover preferences and behavior patterns [77]. The effective learning policy or the recommendation list of the style-fit is prepared to deliver personalized learning service [78].

\section{Models and Methodology}

A unified framework is proposed to systematically evaluate the learning progress and recommend an effective style-fit strategy that facilitates the learners or instructors to enhance the learning performance. Based on the previous research of the authors [79], the model is designed to accommodate pragmatic courses like computer programming where both knowledge and skill are evaluated. As shown in Figure 1, the system is composed of four synergistic modules; the features transformation, the performance prediction, 


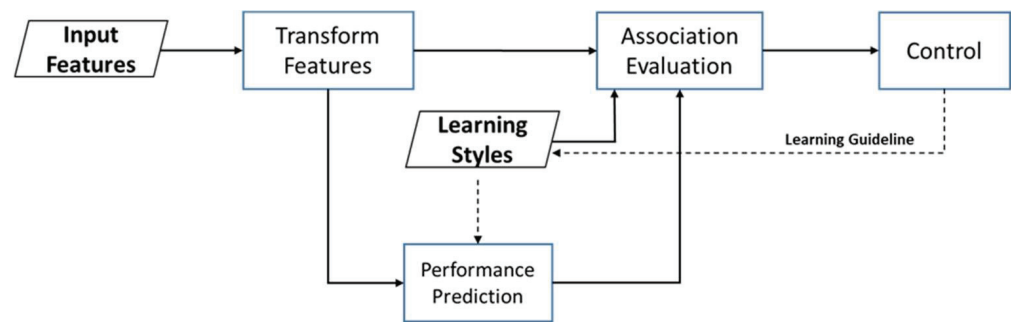

Figure 1 The designated framework for adaptive learning style-fit recommender.

the association evaluation, and the controls module. The rest of this section describes the model and methodology to implement these components.

\subsection{Architecture of the Unified Framework}

The important task of the first module, input features transformation, is to transform a priori set of individual student attributes into meaningful and manageable clusters [20], which would be called students' posterior profile in this paper. As specified in Section 2, these a priori features reflect students' embedded profile, for example, the $\mathrm{AB}, \mathrm{MI}$, and personality traits (PTs). Once being transformed, students' posterior profile shall classify students into manageable groups and enable the interpretable interaction outcomes when cooperating with the other modules of the system.

Based on the students' posterior profile obtained from the first module, the second module of performance prediction is designed to forecast the students' learning performance in terms of the declarative knowledge and the procedural proficiency or skill [80], the ultimate measures of the learning outcome. The association evaluation is the third module in sequence, designed to analyze and identify any relationships of the available learning styles with the students' posterior profiles and the learning performance. Any interaction signals, moderation, or sequential effective relationship should be directed to the fourth module of control.

The control module is based on the paraphrased hypothesis well recognized in the marketing domain [81] that the formative evaluation of the outcome to the customers (students in this case) could be treated as feedback to establish adaptively reinforcing models that yield effective marketing programs (learning facilities or styles in this case) to the increasing performance of the system. 


\subsection{Methodology}

Underlying the components of a unified framework, the design of the methodology is used to control the synergistic working of the core modules. The rest of the section describes the methodology of performance measuring, the feature transformation method, the development of the prediction model, the elaboration of association evaluation, and the outcome evaluation.

\subsubsection{Effective measuring of learning performance}

As the computer programming subject is a pragmatic course, the student is expected to establish both knowledge and skill to a satisfactory or higher level. The rubrics of learning achievement could be scaled as multilevel of a desirable grain. The three-level rubric of good, moderate, and underperformed is chosen for this study to avoid the underfitting or overfitting effect as the input data availability is limited. The learning achievement is measured by two core dimensions of performance: declarative knowledge and procedural proficiency.

The declarative knowledge, called knowledge, represents learner's ability to understand and explain computer programming concepts, theories, and frameworks. The measuring scheme should be in the form of formative or collective scores, e.g., quizzes, exercises report, and midterm or final examination scores. The procedural proficiency, called skills, is the adeptness in converting learners' knowledge into programming skills. These scores are collected from the lab workshop, assignments, class activities, and the speed test.

Classifying students to the appropriate performance level at the beginning of the class is challenging since the difference in distribution pattern of scores is compared with the previous batches. In this study, the scale of measurement is based on the classic Ebel's method of marking [82]. This method assigned the median score as the basic reference of the letter mark scale as well as the overall ability level (defined by the responsible lecturer) for specifying the interval of marks. The five-level ability is presented in terms of the letters A to D and F (failure). The lower limit (LL) factor of grade A for the current batch could be determined and set as the reference point to compute the mark intervals for other grades based on statistical measures of mean $(M)$ and standard deviation (SD). The adopted method for the three rankedorder of this study defined the score range of the Good group was from the lower boundary to the maximum score, estimated by Equation (1). The 
score range of the Satisfactory group was an interval between the Good and Underperformed group, estimated by Equation (2), and the score range of the Underperformed is from the minimum score to the upper boundary, estimated by Equation (3).

$$
\begin{aligned}
\text { Good }= & \{x \varepsilon R \mid M+(S D * L L) \ll x \ll \text { Max }\} \\
\text { Satisfied }= & \{x \varepsilon R \mid M+(S D *(L L-2))<x<M \\
& +(S D * L L)\} \\
\text { Underperformed }= & \{x \varepsilon R \mid M i n \ll x \ll M+(S D *(L L-2))\}
\end{aligned}
$$

where $x$ is a raw score, $R$ is the set of real numbers, Min and Max are the minimum and the maximum scores of students in the consideration.

\subsubsection{Effective posterior profile}

The primary input factors of this study were collected from the cognitive and non-cognitive abilities. The potential $\mathrm{AB}$ and MIs represent the cognitive factors. The PTs reflect the member of the non-cognitive ability. The details of all input variables are presented in Tables $1-3$.

\begin{tabular}{|c|c|c|}
\hline Type & Category & Variable \\
\hline \multirow[t]{11}{*}{ Cognitive } & Academic background(AB) & English language \\
\hline & & Mathematics \\
\hline & & Science \\
\hline & & High school GPA \\
\hline & Multiple intelligences(MIs) & Word smart \\
\hline & & Number smart \\
\hline & & Picture smart \\
\hline & & Body smart \\
\hline & & Music smart \\
\hline & & People smart \\
\hline & & Self-smart \\
\hline \multirow[t]{5}{*}{ Non-cognitive } & Personality traits(PTs) & Neuroticism \\
\hline & & Extraversion \\
\hline & & Openness \\
\hline & & Agreeableness \\
\hline & & Conscientiousness \\
\hline
\end{tabular}

Since the increasing number of input variables may lead to multicollinearity, previous research of the authors proposed a specific transform features

Table 1 List of primary input factors 
Table 2 The big five inventory domains [83]

\begin{tabular}{ll}
\hline Big Five Domain & \multicolumn{1}{c}{ Definition } \\
\hline Neuroticism & $\begin{array}{l}\text { Contrasts emotional stability and even-temperedness with negative } \\
\text { emotionality, such as feeling anxious, nervous, sad, and tense }\end{array}$ \\
Extraversion & $\begin{array}{l}\text { Implies an energetic approach toward the social and material world } \\
\text { and includes traits such as sociability, activity, assertiveness, and } \\
\text { positive emotion }\end{array}$ \\
Openness & $\begin{array}{l}\text { Describes the breadth, depth, originality, and complexity of an } \\
\text { individual's mental and experiential life }\end{array}$ \\
Agreeableness & $\begin{array}{l}\text { Contrasts a prosocial and orientation toward others without } \\
\text { antagonism and includes traits such as altruism, tender-mindedness, } \\
\text { trust, and modesty }\end{array}$ \\
Conscientiousness & $\begin{array}{l}\text { Describes a socially prescribed impulse control that facilitates task } \\
\text { and goal directed behavior, such as thinking before acting, and } \\
\text { following norms and rules }\end{array}$ \\
\hline
\end{tabular}

Table 3 Gardner's seven intelligences [17]

\begin{tabular}{|c|c|}
\hline Intelligence & Description \\
\hline Word smart & $\begin{array}{l}\text { An ability to analyze information and create products involving oral and } \\
\text { written language such as speeches, books, and memos }\end{array}$ \\
\hline Number smart & $\begin{array}{l}\text { An ability to develop equations and proofs, make calculations, and solve } \\
\text { abstract problems }\end{array}$ \\
\hline Picture smart & $\begin{array}{l}\text { An ability to recognize and manipulate large-scale and fine-grained } \\
\text { spatial images }\end{array}$ \\
\hline Body smart & An ability to use one's body to create products or solve problems \\
\hline Music smart & $\begin{array}{l}\text { An ability to produce, remember, and make meaning from different } \\
\text { patterns of sound }\end{array}$ \\
\hline People smart & $\begin{array}{l}\text { An ability to recognize and understand other people's moods, desires, } \\
\text { motivations, and intentions }\end{array}$ \\
\hline Self-smart & $\begin{array}{l}\text { An ability to recognize and understand his or her own moods, desires, } \\
\text { motivations, and intentions }\end{array}$ \\
\hline
\end{tabular}

model that applied principal component analysis (PCA) approach to find the optimal effective factors. The PCA for feature extraction is adopted to preserve all the PC values and the exhaustive feature selection, which is presented in Figure 2.

The features transform aimed to gain an optimal set of effective factors with insightful information [20]. Which the optimal factors were feed as the 


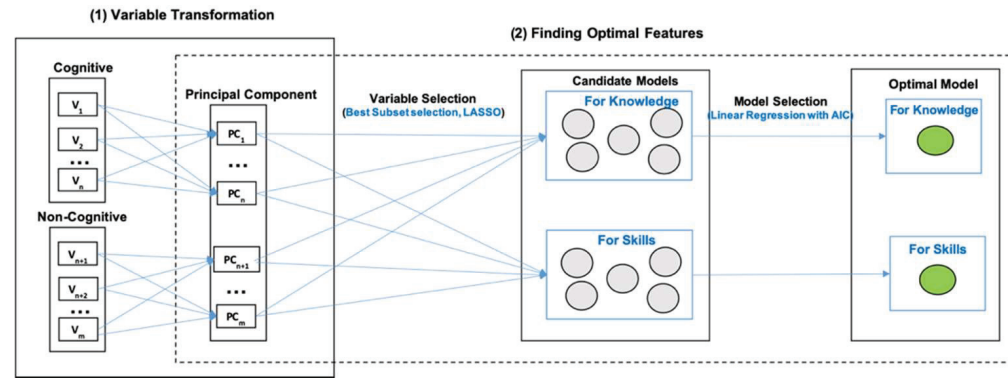

Figure 2 Architecture of the transform features.

input of the prediction model and the intensive association evaluation. This specific process is composed of two subprocesses: variable transformation and variable selection (finding optimal features). The intensive variables transformation is based on the algorithm of the PCA, which can be the process that would be deployed to generate a set of new features (or principal components (PC)). Each PC represents a combination of all original variables, independent of the other PCs. The local relationship of variables in each PC enables the reference to common characteristics of students in the group. Then the extraction process would be performed to optimally find a set of effective PCs. To guarantee the optimality of the selected output of this process, the best subset selection, the well-known complete search method, and the least absolute shrinkage and selection operator (LASSO) were applied in this experiment. Both of the selected methods are based on regression analysis and very reliable [84], invalidating the significance of the relationship between variables and the output of the system.

In the best subset selection method, an exhaustive search for all possible combinations of input variables is done by separating the task into two steps. The first step, which is to identify the best model for each subset, is subjected to the smallest residual sum of squares (RSS). The second step is to globally select the best model from the best of each subset. The selection is subject to the Akaike information criterion (AIC).

The shrinkage method, which is the basis of LASSO [84], is another technique to fit the model by introducing a constrain or regularization of the coefficient estimates. Technically, that is to shrink the coefficient estimates toward zero. This technique penalizes the magnitude of coefficients of features along with minimizing the difference of error between predicted and actual observations. The L1 regularization is a well-known approach of the LASSO [85]. This approach used the absolute value of the magnitude 
of the coefficient as a penalty term as the loss function. LASSO shrinks the less important features coefficient to zero, which is well-suited for feature selection, especially when the number of variables is large.

\subsubsection{Association evaluation method}

Hypothetically, the analysis of the interaction among the students' learning performance, their posterior profile, and learning style preference may lead to systematic guidance for improving student's learning abilities. In this study, two association methods were used to reveal interesting relationships. (1) The association rules method was used to identify the links between characteristics and learning styles of students depending on their performance level. (2) The moderation analysis was done to identify the moderating influences of learning style on the relationship between a student's profile and the learning performance level.

At this stage, the output of the two methods exposed two types of relationships. The association rules have shown the direct association and moderation analysis has shown the interaction effect. The insightful information of two methods has been integrated manually by the researchers and lecturers and is concluded into the learning guideline for students in each group. When this system is extended and integrated with the online learning systems, the learning intelligence dashboard could be used to holistically monitor and report the ongoing adaptive strategies and achievement of the class for continual control.

\subsubsection{Output evaluation (control process)}

The control module is an intelligent process that transformed this framework into an adaptive system. At this stage, this module is designed to recommend or adjust a learning style that fits a particular students' posterior profile. The output of the association evaluation process, represented in terms of direct relation and interaction effect, was evaluated manually. The instructor can interplay with the output of all subprocesses of the association evaluation to find more insightful and accurate learning guidelines. Once the model is extended with the online learning system, the behavior monitor process would collect the students' learning behavior. The control module should adjust students' evaluation automatically by utilizing the association rules and select significant and effective association and powerful moderators. The students' learning behavior would be included in the control process as the refinement parameter, making the model fit with the target students. 


\section{Experimental Design}

A unified framework is a conceptual level, which can be varied in a deeper and detailed level. The scope of this experiment covers the association evaluation, which is the third module of the framework. The exhaustive association evaluation was experimented with to demonstrate the process of gaining interpretable relationships of the posterior profile, learning style-fit, and the desire learning performance. Insights into the reinforcing management of the learning process to enhance the students' learning achievement are provided.

\subsection{Participant}

The participants of this study were the volunteer students who enrolled in the first-year computer programming course, computer programming I. This course is a core subject for the first-year first semester of IT major at SIT, KMUTT. There were 115 complete item sets constituting 55 females and 60 males. All the incomplete records and erroneous data were excluded from the item set.

\subsection{Data Collection and Measuring Tools}

There are two types of input data adopted for recommending the style-fit strategy: the student's posterior profile and the individual learning styles. The first one, the effective posterior profiles, is the output of the transform features. The details of the effective profiles obtained in this study are shown in Table 4. The second type of input is a student's learning styles. This study adopted the index of learning styles (ILS) formulated by [39]. ILS is the measuring tool to assess student's learning preferences using a self-evaluation form consisting of 44 questions (11 questions for each of four dimensions), presented in Table 5.

Although the reliability of ILS was confirmed in extant research [39], this study validated the reliability of the ILS with the pioneer respondents; 40 IT and CS students of SIT , KMUTT. The results show that all dimensions of the questionnaire had the Cronbach's alpha greater than 0.7, the minimum acceptable criterion for reliability.

The learning performance in this study is measured as a performance clustering group, as outlined in Section 3.2.1. The achievement of the student is measured by two core dimensional performances as the declarative knowledge and procedural proficiency (or programming skills) with three 
Table 4 The student's posterior profile.

\begin{tabular}{lcl}
\hline Category & Component & \multicolumn{1}{c}{ Description } \\
\hline Academic background & $\mathrm{AB}_{\mathrm{BAL}}$ & $\begin{array}{l}\text { Group of students who have balanced } \\
\text { combination of the test results in English, } \\
\text { mathematics, science, and the high school GPA. } \\
\text { Gultiple intelligence }\end{array}$ \\
$\mathrm{AB}_{\mathrm{GPA}}$ & $\mathrm{FMI}_{\mathrm{BAL}}$ & $\begin{array}{l}\text { Group of students who have high school GPA, } \\
\text { average in science, and weak in English and } \\
\text { mathematics. } \\
\text { Group of students having a balanced combination } \\
\text { of all intelligences, except mathematics. } \\
\text { Group of students who have outstanding } \\
\text { intelligence in mathematics. } \\
\text { Group of students who have high } \\
\text { conscientiousness. }\end{array}$ \\
\hline
\end{tabular}

ranked order: Good, Satisfactory, and Underperformed. The clustering result is shown in Table 6.

\subsection{Setting of Association Evaluation}

\subsubsection{Setting for association rules analysis}

The association rule analysis was adopted to find three main relationships. The first one is to find the powerful posterior profile of students at different performance levels, that the posterior profile was set as the antecedent of the rules. The second is to expose the learning preference of students in the different clusters, that the students' learning performance was set as the antecedent of the rules. The last is to find effective learning styles that can increase the learning performance of the Satisfactory and Underperformed groups. Consequently, the third experiment was set with the posterior profile and learning style of the students as the antecedent of the rules. For all of those experiments, the students' learning performance, which is the level of knowledge and skills, was set as the consequence of the association analysis.

In this study, the a priori algorithm is adopted for the association rules analysis $[55,86]$. This algorithm is to find the most frequent combination in the dataset and identify the association rules by setting the threshold (support, confidence, and lift). The package arules [87] of the R program were deployed. All antecedents of the original input data (115 datasets) were converted into the interval scale; the student's posterior profile was converted into the dichotomous (as high or low level), and all four dimensions 
Table 5 The index of learning style dimensions and description

\begin{tabular}{|c|c|c|}
\hline Dimension & Style & Description \\
\hline \multirow[t]{3}{*}{ Process } & Active (ACT) & $\begin{array}{l}\text { Active learners tend to retain and understand } \\
\text { information best by doing something active with it such } \\
\text { as discussing or applying it or explaining it to others. }\end{array}$ \\
\hline & Balance $\left(\right.$ Bal $\left._{\text {Pro }}\right)$ & $\begin{array}{l}\text { The learner can learn best for both active and reflective } \\
\text { learning style. }\end{array}$ \\
\hline & Reflective (REF) & Reflective learners prefer to think about it quietly first. \\
\hline \multirow[t]{3}{*}{ Perception } & Sensing (SEN) & $\begin{array}{l}\text { Sensors tend to be patient with details and good at } \\
\text { memorizing facts and doing hands-on (laboratory) work. }\end{array}$ \\
\hline & Balance $\left(\mathbf{B a l}_{\mathrm{Per}}\right)$ & $\begin{array}{l}\text { The learner can learn best for both sensing and intuitive } \\
\text { learning style. }\end{array}$ \\
\hline & Intuitive (INT) & $\begin{array}{l}\text { Intuitive learner may be better at grasping new concepts } \\
\text { and are often more comfortable than sensors with } \\
\text { abstractions and mathematical formulations. }\end{array}$ \\
\hline \multirow[t]{3}{*}{ Input } & Visual (VIS) & $\begin{array}{l}\text { Visual learners remember best what they see such as } \\
\text { pictures, diagrams, flow charts, timelines, films, and } \\
\text { demonstrations. }\end{array}$ \\
\hline & Balance $\left(\mathbf{B a l}_{\text {Inp }}\right)$ & $\begin{array}{l}\text { The learner can learn best for both visual and verbal } \\
\text { learning style. }\end{array}$ \\
\hline & Verbal (VER) & $\begin{array}{l}\text { Verbal learners get more out of words such as written } \\
\text { and spoken explanations. }\end{array}$ \\
\hline \multirow[t]{3}{*}{ Understand } & Sequence (SEQ) & $\begin{array}{l}\text { Sequential learners tend to gain understanding in linear } \\
\text { steps, with each step following logically from the } \\
\text { previous one. }\end{array}$ \\
\hline & Balance $\left(\mathbf{B a l}_{\text {Und }}\right)$ & $\begin{array}{l}\text { The learner can learn best for both sequence and global } \\
\text { learning style. }\end{array}$ \\
\hline & Global (GLO) & $\begin{array}{l}\text { Global learners tend to learn in large jumps, absorbing } \\
\text { material almost randomly without seeing connections, } \\
\text { and then suddenly "getting it." }\end{array}$ \\
\hline
\end{tabular}

Table 6 Students' performance clustering

\begin{tabular}{lccc}
\hline Specific Performance & Good & Satisfactory & Underperformed \\
\hline Knowledge & 18 & 73 & 24 \\
Skills & 19 & 73 & 23 \\
\hline
\end{tabular}


of learning styles were converted into three values of styles (the LHS, the balance of style, and the RHS). In this case, the level of knowledge and skills has been experimented with separately.

The input data of this study are imbalanced and limited in terms of students' amount in each cluster. Most students are in the Satisfactory group, as shown in Table 6 . The confidence, support, and lift values were configured differently when mining important rules in each student cluster. Lift value higher than 1.8 is required to be strictly affirmative in every discovered rule for assuring the statistical significance [64, 86, 87]. For the majority class (Satisfactory group), the thresholds of support and confidence were set as 0.1 and 0.7 in respective order. Those for the minority classes (Good and Underperformed groups) were set at 0.08 and 0.5 .

\subsubsection{Setting for moderation analysis}

The moderation analysis was adopted to probe the conditional effect of student's posterior profile on their learning performance when adopted different learning styles. The moderation analysis was performed according to the computational tool called the PROCESS [65, 67] which is available as an embedded function in the SPSS. The student's posterior profile (antecedent), student's learning preference (moderator), and the level of knowledge and skills (consequence) were the same set as applied in the association rules analysis. The Johnson-Neyman was used to compute the range of significance and simple slopes for the interaction analyses. All analyses were two-tailed and the significance thresholds were set with the $p$-value as 0.05 . The bootstrap resampling was used to estimate a $95 \%$ confidence interval for the indirect effect using 5000 bootstrap samples [65].

\section{Results}

This section reports the experimental results, including the distribution of students' learning styles, evaluation of the association rules, and evaluation of moderation analysis.

\subsection{Learning Styles Distribution}

The student learning style is considered as one of the important input variables for the association evaluation module. Based on the data collection, according to the ILS self-evaluation, the obtained distribution of students' learning styles according to the four dimensions of learning style is shown 
Table 7 Learning styles distribution

\begin{tabular}{lcccccccccccc}
\hline & \multicolumn{4}{c}{ Process } & \multicolumn{4}{c}{ Perception } & \multicolumn{3}{c}{ Input } & \multicolumn{3}{c}{ Understand } \\
\cline { 2 - 14 } Dimension & ACT & Bal & REF & SEN & Bal & INT & VIS & Bal & VER & SEQ & Bal & GLO \\
\hline Number & 41 & 65 & 9 & 53 & 59 & 3 & 61 & 50 & 4 & 9 & 95 & 11 \\
\hline
\end{tabular}

in Table 7. Noticeably, students tend to have balanced styles of learning in every dimension except the input dimension, where the visual learners are the highest. However, the number of the active and the sensing learner (of the process and the perception dimensions, respectively) is close to the number of the balanced style. This implies that the learning preference of students in this experiment is in line with the science and engineering students reported in [88], which indicated the preferred learning styles as \{active, sensing, visual, and $\left.\mathrm{Bal}_{\text {Und }}\right\}$. Next, we explore the relationship of these learning styles with the students' profile and their expected learning performance.

\subsection{Evaluation of the Association Rules}

The association rule analysis is used to explore three main relationships, as mentioned in Section 4.3.1. The most significant (or interesting) rules are listed in Tables 8-10.

The rules in Table 8 expose the characteristics of students in each measure of knowledge and skill sorted by order of attainment. The rules confirm the effectiveness of the posterior profile of the students (defined in Section 4.2) as the powerful factors for classifying the attaining level of programming knowledge and skills. Rules number 1 and 7 expose the characteristics of the students who excelled in computer programming study (knowledge and skills, respectively) as of those with a high level of three properties in the posterior profile: the $\mathrm{AB}_{\mathrm{BAL}}$ (a well-rounded knowledge), $\mathrm{MI}_{\mathrm{MAT}}$ (outstanding intelligence in mathematics and logic), and $\mathrm{PT}_{\mathrm{CON}}$ (high conscientiousness). Whereas, the attainment of Satisfactory and Underperformed is associated with the low level of the $\mathrm{MI}_{\mathrm{MAT}}$, which is observable in the remaining rules.

Table 9 exposes the learning preferences of students in each cluster. The experimental result (rules number 11 and 13) shows that excellent students are opened or neutral to the process (active and reflective styles) and also to the input dimension (visual and verbal). The confidence levels may not be high, but both measures' conformity helps to validate the relationship. Satisfactory students prefer to learn with the visual learning style (rules number 12 and 14). This evidence reveals that there are certain associations between learning performance and learning styles. 
Table 8 The association rules between student's profile and learning performance

\begin{tabular}{|c|c|c|c|c|c|}
\hline \multirow[b]{2}{*}{ No } & \multicolumn{2}{|r|}{ Rules } & \multicolumn{3}{|c|}{ Threshold Value } \\
\hline & Antecedences & Consequence & Sup. & Conf. & Lift \\
\hline 1 & $\begin{array}{l}\mathrm{AB}_{\mathrm{BAL}}=\text { High } \\
\mathrm{AND} \\
\mathrm{FMI}_{\mathrm{MAT}}=\mathrm{High} \\
\mathrm{AND} \mathrm{PT}_{\mathrm{COV}}=\mathrm{High}\end{array}$ & Knowledge $=$ Good & 0.1130 & 0.8125 & 3.7375 \\
\hline 2 & $\mathrm{FMI}_{\mathrm{MAT}}=$ High & Knowledge $=$ Good & 0.1565 & 0.5625 & 2.5878 \\
\hline 3 & $\begin{array}{l}\mathrm{AB}_{\mathrm{GPA}}=\text { High } \\
\mathrm{AND} \\
\mathrm{FMI}_{\mathrm{MAT}}=\text { Low } \\
\mathrm{AND} \\
\mathrm{PT}_{\mathrm{CON}}=\text { High }\end{array}$ & Knowledge $=$ Satisfied & 0.1652 & 0.8261 & 1.3194 \\
\hline 4 & $\begin{array}{l}\mathrm{AB}_{\mathrm{BAL}}=\text { High } \\
\mathrm{AND} \\
\mathrm{FMI}_{\mathrm{MAT}}=\text { Low } \\
\mathrm{AND} \mathrm{PT}_{\mathrm{CON}}=\text { Low }\end{array}$ & Knowledge $=$ Satisfied & 0.1130 & 0.7647 & 1.2214 \\
\hline 5 & $\begin{array}{l}\mathrm{AB}_{\mathrm{BAL}}=\text { Low AND } \\
\mathrm{FMI}_{\mathrm{MAT}}=\text { Low } \\
\mathrm{AND} \mathrm{PT}_{\mathrm{CON}}=\text { Low }\end{array}$ & Knowledge $=$ Underperformed & 0.0870 & 0.3030 & 1.9360 \\
\hline 6 & $\begin{array}{l}\mathrm{AB}_{\mathrm{GPA}}=\text { Low AND } \\
\mathrm{FMI}_{\mathrm{MAT}}=\mathrm{High}\end{array}$ & Skills $=$ Good & 0.0870 & 0.7143 & 3.5714 \\
\hline 7 & $\begin{array}{l}\mathrm{AB}_{\mathrm{BAL}}=\text { High } \\
\mathrm{AND} \\
\mathrm{FMI}_{\mathrm{MAT}}=\text { High } \\
\mathrm{AND} \\
\mathrm{PT}_{\mathrm{CON}}=\text { High }\end{array}$ & Skills $=$ Good & 0.0957 & 0.6875 & 3.4375 \\
\hline 8 & $\mathrm{FMI}_{\mathrm{MAT}}=$ High & Skills=Good & 0.1391 & 0.5000 & 2.500 \\
\hline 9 & $\begin{array}{l}\mathrm{AB}_{\mathrm{GPA}}=\text { Low } \mathrm{AND} \\
\mathrm{FMI}_{\mathrm{MAT}}=\text { Low } \\
\mathrm{AND} \\
\mathrm{PT}_{\mathrm{CON}}=\text { Low }\end{array}$ & Skills $=$ Satisfied & 0.0957 & 0.9167 & 1.4441 \\
\hline 10 & $\begin{array}{l}\mathrm{AB}_{\mathrm{BAL}}=\text { Low } \mathrm{AND} \\
\mathrm{FMI}_{\mathrm{MAT}}=\text { Low } \\
\mathrm{AND} \\
\mathrm{PT}_{\mathrm{CON}}=\text { Low }\end{array}$ & Skills $=$ Underperformed & 0.0870 & 0.3030 & 1.8341 \\
\hline
\end{tabular}


Table 9 The association rules between student's learning preference and performance

\begin{tabular}{llcccc}
\hline \multirow{2}{*}{ No } & \multicolumn{3}{c}{ Rules } & Threshold Value \\
\cline { 2 - 6 } & Antecedences & Consequence & Sup. & Conf. & Lift \\
\hline 11 & $\begin{array}{l}\text { Process = balance } \\
\text { AND } \\
\text { input = balance }\end{array}$ & Knowledge = Good & 0.0957 & 0.3548 & 1.6323 \\
12 & $\begin{array}{l}\text { Process = balance } \\
\text { AND input = visual }\end{array}$ & Knowledge = Satisfied & 0.2000 & 0.7419 & 1.1850 \\
13 & $\begin{array}{l}\text { Process=balance } \\
\text { AND } \\
\text { input = balance }\end{array}$ & Skills = Good & 0.0870 & 0.3704 & 1.8519 \\
14 & $\begin{array}{l}\text { Process = active } \\
\text { AND Input = visual }\end{array}$ & Skills = Satisfied & 0.1130 & 0.8125 & 1.2800 \\
\hline
\end{tabular}

Table 10 extends the exposure that yields a better understanding of the systematic patterns of the studying in each cluster. The association rules combine the students' profile and their learning preference as the antecedent of the analysis. In Rule 15, where the profiles of the successful students (Rule 1) combined with the neutral style of Understand confirmed that students have superb knowledge in computer programming study with the confidence value around $85 \%$. Another interesting finding as exposed in rules number 16 and 17 is that sensing style (SEN) or practicing with patience is quite significant (Conf. around $77 \%-79 \%$ ) to craft up those students lacking some excellent properties, e.g., holding $\mathrm{MI}_{\mathrm{MAT}}$ (good in mathematics) but lacking either of $\mathrm{AB}_{\mathrm{BAL}}$ (balanced knowledge) or $\mathrm{PT}_{\mathrm{CON}}$ (good conscientiousness). This association is also true for attaining excellence in skills (rule number 23). This is with a bit lower confidence value of 71\%. Rules 18-22 (for knowledge) and Rule 24 (for skills) show the significant association of visual (using high level media or abstraction to demonstrate) as learning style and the attainment in the satisfied level for both knowledge (Conf. $=100 \%)$ and skills $\left(\right.$ Conf. $=92 \%$ ) for those who are weak in $\mathrm{MI}_{\mathrm{MAT}}$ (math and logic) but strong in other all-round properties, i.e., $\mathrm{AB}_{\mathrm{BAL}}$ or $\mathrm{AB}_{\mathrm{GPA}}$, or with good concentration (PT3). The association of visual and satisfied attainment levels may reflect its double-edged sword effect, which, on the one hand, provides digestible or easy-to-understand essence. Still, on the other hand, this easing may prevent students from sensing or exercising for deep details. 
Table 10 The association rules between student's profile, learning styles, and performance

\begin{tabular}{|c|c|c|c|c|c|}
\hline \multirow[b]{2}{*}{ No } & \multicolumn{2}{|c|}{ Rules } & \multicolumn{3}{|c|}{ Threshold Value } \\
\hline & Antecedences & Consequence & Sup. & Conf. & Lift \\
\hline 15 & $\begin{array}{l}\mathrm{AB}_{\mathrm{BAL}}=\text { High AND } \\
\mathrm{FMI}_{\mathrm{MAT}}=\text { High AND } \\
\mathrm{PT}_{\mathrm{CON}}=\text { High AND } \\
\text { Understand = balance }\end{array}$ & Knowledge $=$ Good & 0.0957 & 0.8462 & 3.8923 \\
\hline 16 & $\begin{array}{l}\mathrm{AB}_{\mathrm{BAL}}=\text { High AND } \\
\mathrm{FMI}_{\mathrm{MAT}}=\text { High AND } \\
\text { Perception = sensing }\end{array}$ & Knowledge $=$ Good & 0.0957 & 0.7857 & 3.6143 \\
\hline 17 & $\begin{array}{l}\mathrm{FMI}_{\mathrm{MAT}}=\text { High AND } \\
\mathrm{PT}_{\mathrm{CON}}=\text { High AND } \\
\text { Perception = sensing }\end{array}$ & Knowledge $=$ Good & 0.0870 & 0.7692 & 3.5385 \\
\hline 18 & $\begin{array}{l}\mathrm{AB} 2=\text { High AND } \\
\mathrm{FMI}_{\mathrm{MAT}}=\text { Low AND } \\
\mathrm{PT}_{\mathrm{CON}}=\text { High AND } \\
\text { Input }=\text { visual }\end{array}$ & Knowledge $=$ Satisfied & 0.1043 & 1.0000 & 1.5972 \\
\hline 19 & $\begin{array}{l}\mathrm{AB}_{\mathrm{BAL}}=\text { High AND } \\
\text { FMI }_{\mathrm{MAT}}=\text { Low AND } \\
\text { Perception = balance } \\
\text { AND Input = visual }\end{array}$ & Knowledge $=$ Satisfied & 0.0957 & 1.0000 & 1.5972 \\
\hline 20 & $\begin{array}{l}\mathrm{AB}_{\mathrm{BAL}}=\text { High AND } \\
\mathrm{FMI}_{\mathrm{MAT}}=\text { Low AND } \\
\text { Process = balance AND } \\
\text { Input }=\text { visual }\end{array}$ & Knowledge $=$ Satisfied & 0.1217 & 1.0000 & 1.5972 \\
\hline 21 & $\begin{array}{l}\mathrm{FMI}_{\mathrm{MAT}}=\text { Low AND } \\
\mathrm{PT}_{\mathrm{CON}}=\text { High AND } \\
\text { Perception = balance } \\
\text { AND Input = visual }\end{array}$ & Knowledge $=$ Satisfied & 0.0870 & 1.0000 & 1.5972 \\
\hline 22 & $\begin{array}{l}\mathrm{FMI}_{\mathrm{MAT}}=\text { Low AND } \\
\mathrm{PT}_{\mathrm{CON}}=\text { High AND } \\
\text { Process = balance AND } \\
\text { Input }=\text { visual }\end{array}$ & Knowledge $=$ Satisfied & 0.0957 & 1.0000 & 1.5972 \\
\hline 23 & $\begin{array}{l}\mathrm{AB}_{\mathrm{BAL}}=\text { High AND } \\
\mathrm{FMI}_{\mathrm{MAT}}=\text { High AND } \\
\text { Perception = sensing }\end{array}$ & Skills $=$ Good & 0.0870 & 0.7134 & 3.5714 \\
\hline 24 & $\begin{array}{l}\mathrm{AB}_{\mathrm{BAL}}=\text { High } \mathrm{AND} \\
\mathrm{FMI}_{\mathrm{MAT}}=\text { Low AND } \\
\text { Process = balance AND } \\
\text { Input = visual }\end{array}$ & Skills $=$ Satisfied & 0.1130 & 0.9286 & 1.4628 \\
\hline
\end{tabular}




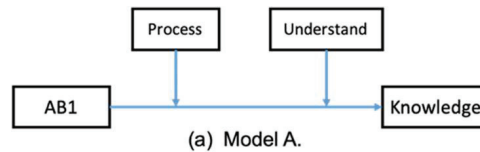

$F(7,107)=5.4923, p<.0000, R^{2}=.2643$

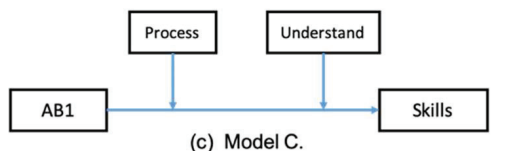

(c) Model C.

$F(7,107)=2.9690, p=.0069, R^{2}=.1626$

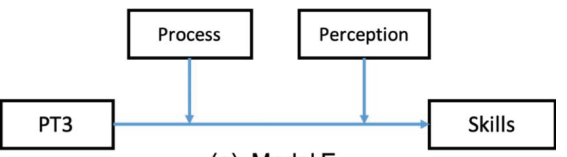

(e) Model E.

$F(7,107)=3.5946, p=.0016, R^{2}=.1904$

Figure 3 The significant moderation models.

\subsection{Evaluation of the Moderation Analysis}

As mentioned in Section 4.3.2, the macro PROCESS adopted in this study examined the interaction effect of students' learning styles on the relationship between students' posterior profile and learning performance (knowledge and skills). There are two steps for evaluating the results of the interaction effect (output of the PROCESS); the first step is to find significant models, and then to examine the interaction effect (or moderators) of each significant model.

In the first step, the cooperation of learning dimensions is determined as the moderator and examined with the exhaustive experiment. The significant model must have a statistically significant value (or $p$-value) less than 0.05 . In this step, five significant models were obtained, and the conceptual diagrams of those models (A-E) are shown in Figure 3(a)-(e). However, the results obtained from this step could only reveal significant models but is not able to specify a type of interaction effect. The next step is to evaluate the type of interaction effect, the enhancement of interaction effect (increasing the effect of profile on performance) or buffering interaction effect (decreasing the effect of profile on performance). This study aims to find the learning style that helps improve students learning performance, thus enhancing the interaction effect is focused.

In the second step, the significant models are examined to indicate any interaction effects and their implication. 
Table 11 The benchmark of the students' posterior profile

\begin{tabular}{lcccc}
\hline Antecedence & Consequence & \multicolumn{3}{c}{ Output Measurement } \\
\cline { 3 - 5 } & & $F$ & $p$-Value & $R^{2}$ \\
\hline AB1 & Knowledge & 24.912 & $<0.0000$ & 0.181 \\
PT3 & Knowledge & 14.315 & $<0.0000$ & 0.112 \\
AB1 & Skills & 11.389 & $=0.001$ & 0.092 \\
FMI2 & Skills & 23.927 & $<0.0000$ & 0.175 \\
PT3 & Skills & 8.284 & $<0.0000$ & 0.068 \\
\hline
\end{tabular}

First, the benchmark (or baseline) is determined for underlying the measure of the power of the interaction effect. The moderation analysis (or macro PROCESS), adopted in this study is based on the linear regression model [65]. Thus, the simple regression of the individual factor is set as the benchmark. Table 11 shows the statistical characteristics of the five significant benchmarking models. Compared to these baselines, the capability of a learning style of a specific dimension in enhancing the positive interaction of a student and his performance can be analyzed. A very straight rule is that the higher the value of the constant and a beta of the interacted regressed line is, the higher the enhancement of the learning style can be. Additionally, since the level of enhancement can be different for each subgroup in a cluster of students, this could give insights into the distinctive rules for the universal enhancement moderator and the specific enhancement moderator.

Second, the conditional effect of learning styles on the relationship between students' posterior profile and their learning performance is considered. As mentioned in Section 4.2, each learning style dimension contains three value of learning styles (the left-hand side, balancing or natural, and the right-hand side). The exhaustive combination of the learning styles of the significant models (results of the first step) is examined. In this case, all of the interaction effects are compared with the baseline. Only significantly enhancing interaction effects and baselines are shown in Figures 4-8.

In Figure 4, Model A demonstrates the cooperative interaction effect of the Process and Understand dimensions on the relationship between $\mathrm{AB}_{\mathrm{BAL}}$ and students' knowledge. This model exposed three specific enhancement moderators. The ACT-SEQ (coordination of the active and sequence learning style) and REF-GLO (coordination of the reflective and global learning style) tend to amplify the programming knowledge of any students who have a good learning background $\left(\mathrm{AB}_{\mathrm{BAL}}=\right.$ High), whereas the REF$\mathrm{Bal}_{\text {Und }}$ (coordination of the reflective and balancing learning style) tends to 


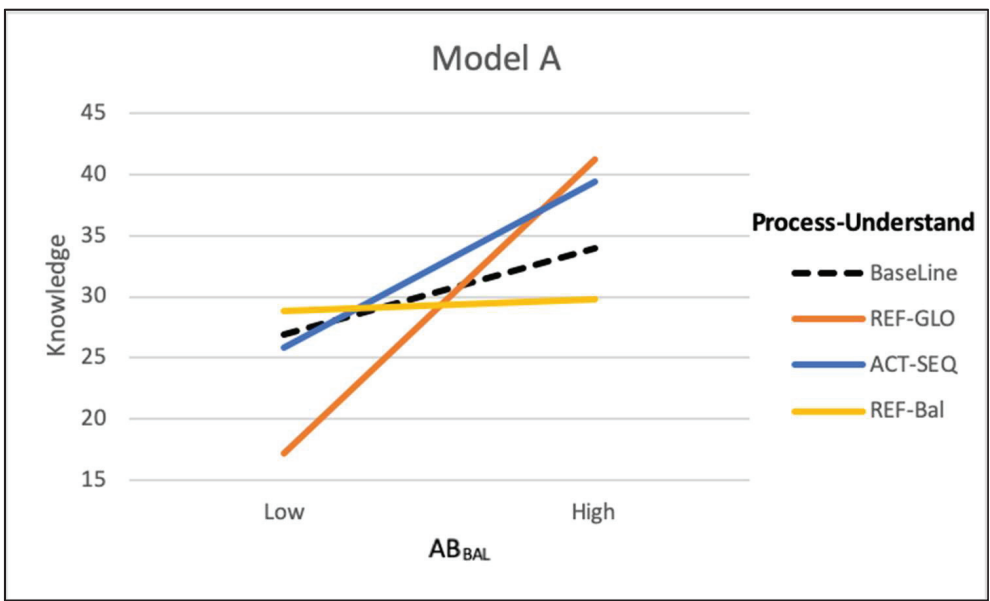

Figure 4 The interaction effect of Model A.

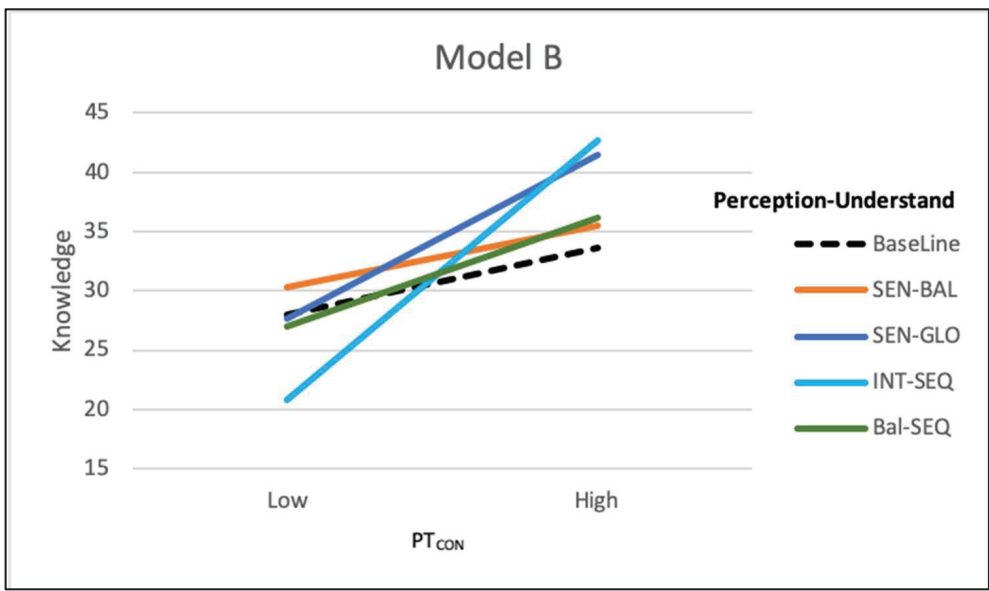

Figure 5 The interaction effect of Model B.

amplify the programming knowledge of the low learning background students $\left(\mathrm{AB}_{\mathrm{BAL}}=\mathrm{Low}\right)$.

As seen in Figure 5, Model B demonstrates the cooperative interaction effect of the Perception and Understand dimensions on the relationship between $\mathrm{PT}_{\mathrm{CON}}$ and students' knowledge. This model exposed a universal enhancement moderator and three specific enhancement moderators. The SEN-Bal Und (coordination of the sensing and neutral of Understand learning 


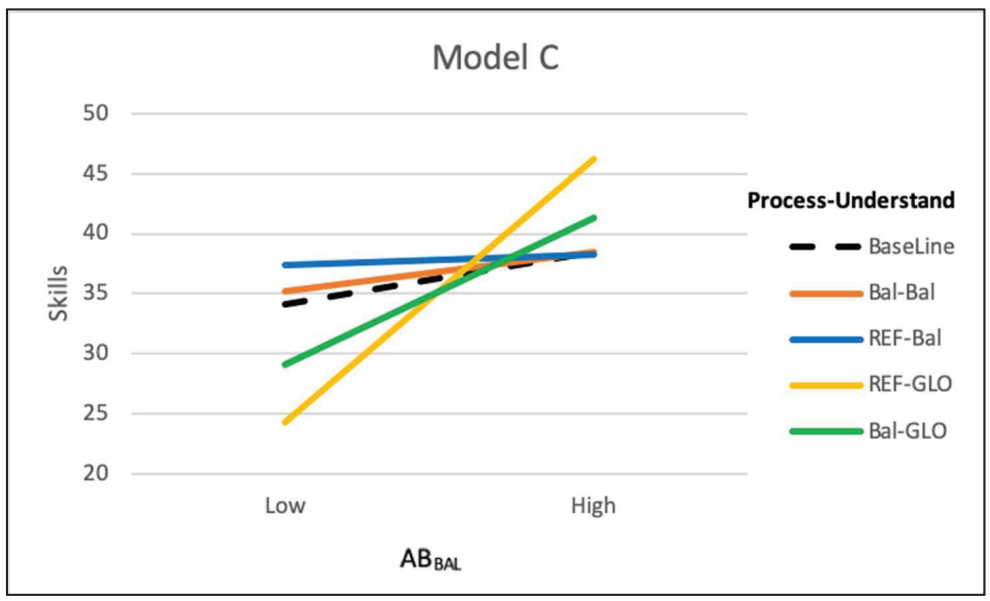

Figure 6 The interaction effect of Model C.

style) is the universal moderator, which can amplify the programming knowledge of all students, whereas the SEN-GLO (coordination of the sensing and global learning style), INT-SEQ (coordination of the intuitive and sequence learning style), and $\mathrm{Bal}_{\mathrm{Pec}}-\mathrm{SEQ}$ (coordination of the neutral of the Perception and sequence learning style) are the specific enhancement moderator, which can amplify the programming knowledge of the high conscientiousness student $\left(\mathrm{PT}_{\mathrm{CON}}=\right.$ High $)$.

In Figure 6, Model $\mathrm{C}$ demonstrates the interaction effect of Process and Understand learning style on the relationship between $\mathrm{AB}_{\mathrm{BAL}}$ and student's skills. This model exposed four specific enhancement moderators. The REF-GLO (coordination of the reflective and global learning style) and $\mathrm{Bal}_{\text {Pro }}-\mathrm{GLO}$ (coordination of the neutral of Process and global learning style) tend to amplify the programming skills of all students who have a good learning background $\left(\mathrm{AB}_{\mathrm{BAL}}=\right.$ High), when the $\mathrm{Bal}_{\mathrm{Pro}}-\mathrm{Bal}_{\text {Und }}$ (coordination of the neutral of Process and neutral of Understand) and the REF-Bal $\left.\right|_{U n d}$ (coordination of reflective learning style and the neutral of Process) tend to amplify the programming skills of the low learning background students $\left(\mathrm{AB}_{\mathrm{BAL}}=\right.$ Low $)$.

In Figure 7, Model D demonstrates the interaction effect of Process and Perception learning style on the relationship between $\mathrm{FMI}_{\mathrm{MAT}}$ and student's skills. This model exposed two universal enhancement moderators and a specific enhancement moderator. The REF-SEN (coordination of the reflective and sensing learning style) and $\mathrm{Bal}_{\mathrm{Pro}}-\mathrm{SEN}$ (coordination of the 


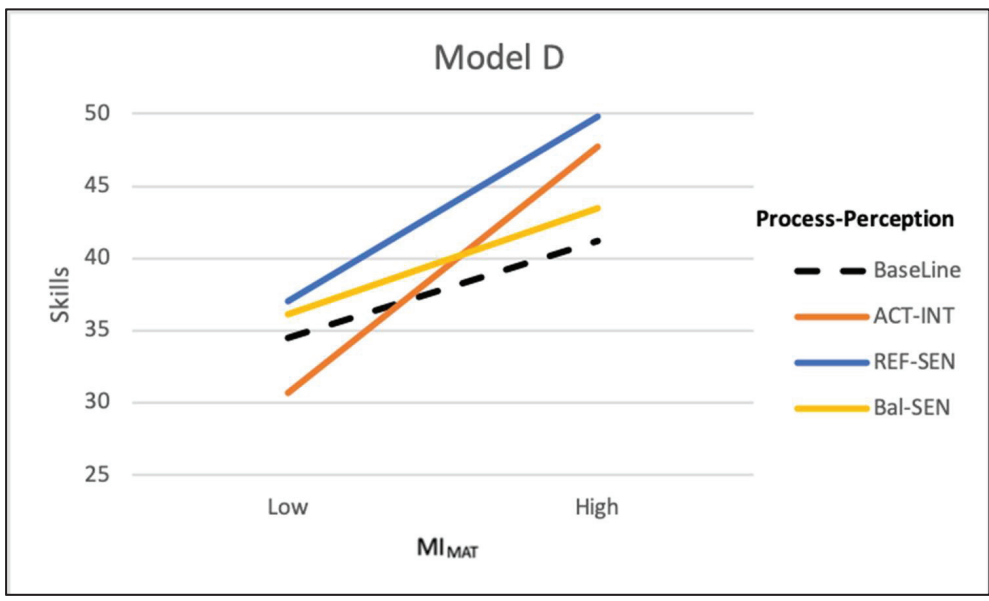

Figure 7 The interaction effect of Model D.

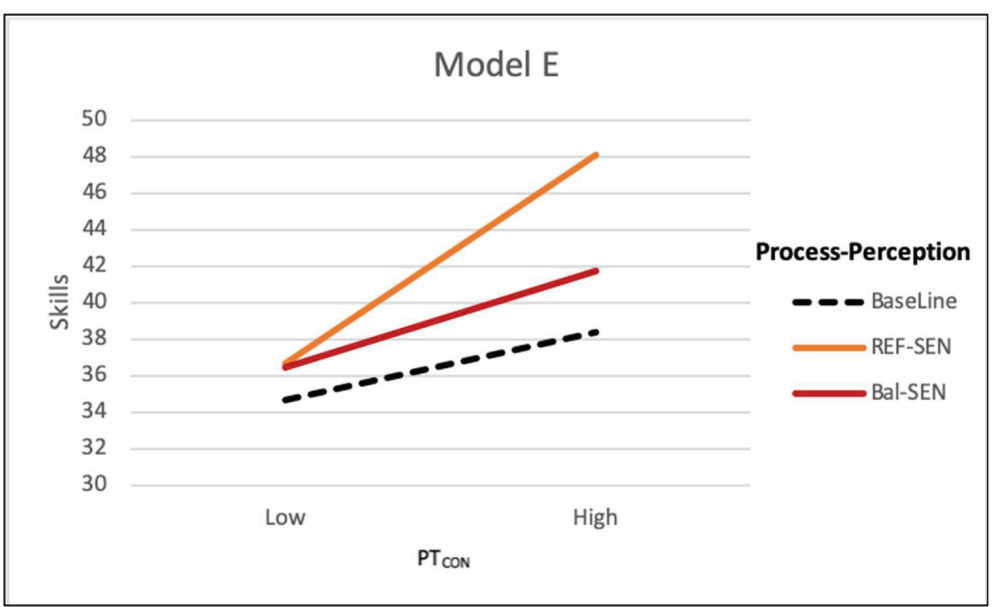

Figure 8 The interaction effect of Model E.

neutral of Process and sensing learning style) are the universal moderators, which can amplify the programming skills of all students, whereas ACTINT (coordination of the active and intuitive learning style) tends to amplify the programming skills of the high mathematical ability $\left(\mathrm{FMI}_{\mathrm{MAT}}=\right.$ High). Moreover, the interaction effect shows that the REF-SEN is the powerful learning style whose highest value of this line is close to the total score of this part. 
For Figure 8, Model E demonstrates the interaction effect of Process and Perception learning style on the relationship between $\mathrm{PT}_{\mathrm{CON}}$ and student's skills. This model exposed two universal enhancement moderators: the REFSEN (coordination of the reflective and sensing learning style) and the $\mathrm{Bal}_{\text {Pro }}-\mathrm{SEN}$ (coordination of the neutral of Process and sensing learning style) to amplify the programming skills of all students.

The output of the moderation analysis insisted that the student's learning style has an interaction effect on the relationship between students' profile and their learning performance. This study defined the two types of significant enhancement moderators: the universal enhancement moderator and the specific enhancement moderator. The universal enhancement moderator is the interaction effect effective for all students, while the specific enhancement moderator is the interaction effect for the particular students.

The universal moderator of this study is composed of the SEN-Bal ${ }_{U n d}$, REF-SEN, and $\mathrm{Bal}_{\mathrm{Pro}}-\mathrm{SEN}$. The SEN-Bal ${ }_{\text {Und }}$ is recommended for increasing learning knowledge and the REF-SEN and/or $\mathrm{Bal}_{\mathrm{Pro}}-\mathrm{SEN}$ is recommended for increasing learning skills. Among the universal moderators, the SEN (sensing) learning style is the mutual coordination learning style. In general, the sensory learners prefer learning by doing [39, 89], and they need more practice and well-established examples [46, 89]. This characteristic matches with the nature of the computer programming subject. To encourage the learners, the lecturers should provide details of programming syntax and facts that need to be learned based on activities found in real life [46, 89, 90]. Moreover, the question-and-answer method, the problem-solving teaching strategy, and the extra example or exercise should be included [91]. The balancing (or neutral) between two poles of each dimension is the ideal learning style because learners can learn best with all styles in that dimension $[39,89]$. Therefore, the students who can balance their learning preferences tend to receive learning information better than the other students. This may be the reason why the $\mathrm{Bal}_{\text {Und }}$ and $\mathrm{Bal}_{\text {Pro }}$ are a part of universal enhancement moderators. The reflection is another learning style in the universal moderator, which was reported from previous computer programming studies as one of the preferred styles of the Excellent students [44]. Although reflection learners prefer to think and work alone [89], they tend to collect, analyze, and review the material carefully before taking action. The lecturer should alternate lectures with occasional pauses. Students are allowed enough time to reflect individually on what they have learned. Reflective learners gain more from the solution method of the homework or example; thus, the lecturer might assign the self-study such as programming practice and give 
Table 12 The alternative learning style for raising knowledge

\begin{tabular}{lc}
\hline Specific Profile & Alternative Learning Style \\
\hline $\mathrm{AB}_{\mathrm{BAL}}=$ Low & REF-Bal $_{\text {Und }}$ \\
$\mathrm{AB}_{\mathrm{BAL}}=$ High & ACT-SEQ, REF-GLO \\
$\mathrm{PT}_{\mathrm{CON}}=$ High & Bal $_{\text {Per-SEQ, SEN-GLO, INT-SEQ }}$ \\
\hline
\end{tabular}

Table 13 The alternative learning style for raising skills

\begin{tabular}{|c|c|}
\hline Specific Profile & Alternative Learning Style \\
\hline $\mathrm{AB}_{\mathrm{BAL}}=\mathrm{Low}$ & $\mathrm{Bal}_{\text {Pro }}-\mathrm{Bal}_{\text {Und }}, \mathrm{REF}-\mathrm{Bal}_{\text {Und }}$ \\
\hline $\mathrm{AB}_{\mathrm{BAL}}=$ High & REF-GLO, BalPro-GLO \\
\hline $\mathrm{FMI}_{\mathrm{MAT}}=$ High & ACT-INT \\
\hline
\end{tabular}

the solution [91]. The universal enhancement moderators help the lecturers to design their appropriate traditional class (or the general classroom) to support all students.

Although universal moderators can be applied to all students, the style-fit learning approach can help learners to learn more effectively. The provision of specific enhancement moderators can be treated as an alternative choice for the students, especially those who are unmatchable with the universal learning style. The lecturers can divide the students into small groups by using their profile, such as a group of low $\mathrm{ABs}\left(\mathrm{AB}_{\mathrm{BAL}}=\mathrm{Low}\right)$. For this group of students, the lecturer may adopt a specific teaching recommendation, e.g., the REF-Bal Und for amplifying knowledge and skills, or adopt $\mathrm{Bal}_{\mathrm{Pro}}-\mathrm{Bal}_{\mathrm{Und}}$, to amplify the skills. Hence, having a set of alternative enhancement moderators can flexibly support the best-fit strategic management for adaptive learning classroom or environment. For this experiment, the alternative learning styles for improving the computer programming knowledge and skills, retrieved from the significant lines observable in Figures 5-8, are shown in Tables 12 and 13 , respectively.

\section{Discussion}

Results of intensive association evaluation reveal the insight into four main points.

The first point is that the posterior profile of students has a certain association with their learning performance. The excellent students tend to have a good profile of $\left(\mathrm{AB}_{\mathrm{BAL}}=\right.$ High, $\mathrm{FMI}_{\mathrm{MAT}}=$ High, and $\mathrm{PT}_{\mathrm{CON}}=$ High $)$, 
whereas the Satisfactory and Underperformed students tend to have the lower ability in mathematics and logic $\left(\mathrm{FMI}_{\mathrm{MAT}}=\mathrm{Low}\right)$. Moreover, the experimental result is consistent with previous research $[12,14,20]$, that the ability in mathematics and logic $\left(\mathrm{FMI}_{\mathrm{MAT}}\right)$ is a powerful indicator for indicating the success in computer programming study. This insight may help the lecturers to design their class, such as cluster grouping students by their mathematical ability, or suggest the low ability students to enroll in precourse or self-learning in mathematical and logic for computer study (e.g., the Discrete Mathematics or the Computational Logic).

The second point is that students who have a broad learning preference (or neutral) tend to have a better learning performance than specific learning preferences. Excellent students have a broad learning style than Satisfactory, which may be the reason for success. This insight may help the lecturers to design their class in such a way of customizing the teaching environment and/or method to accommodate the specific learning style of the specific group.

The third point is that enhancing significant moderators for which their interaction effect was higher than the benchmark. The universal enhancement moderator had a significant interaction effect for all students, composed of the SEN-Bal ${ }_{U n d}$, REF-SEN, and $\mathrm{Bal}_{\text {Pro }}-\mathrm{SEN}$. While the specific enhancing moderator was the alternative for the specific students (their learning preference mismatches with the universal learning style) such as the low ABs $\left(\mathrm{AB}_{\mathrm{BAL}}=\right.$ Low $)$, learners may adopt REF-Bal ${ }_{\text {Und }}$ for increasing their learning performance.

The last point is the limitation of the association evaluation. The imbalance and limit in the size of the minority input data in this study lead to the limit of the significant rules. For enhancing the precision and accuracy of the model, the future experiment should collect student data for the next batch. Each module of this proposed framework operates independently of the others. This model can be flexibly deployed alongside a course proceeding or course-after-course basis.

\section{Conclusion and Future Work}

This paper proposed a unified framework (1) for educators to facilitate the learning environment and materials in the computer programming course, and (2) for systematically reinforcing learners in each independent group to enhance achievement in the course. The study is scoped to only the first course in computer programming and designed to evaluate students' 
attributes and ongoing or formative learning outcome for suggesting the effective style-fit strategy that facilitates learners to enhance their learning performances in terms of knowledge and skill. The obtained results show that the system can evaluate the relationship of student profile, learning style, and the performance prediction for recommending feedback that could improve or facilitate the learning process in a systematic, unified manner. The relationship among these attributes is evaluated using the association rule and moderation analysis. The association rule, by a priori algorithm, insists that the posterior profile was associated with learning performance, and the abilities in mathematics and logic $\left(\mathrm{MI}_{\mathrm{MAT}}\right)$ were the strongest profile associated with the success in computer programming study. The learning preference of students had a relationship with their learning performance. The learners in the Excellent group had a broader learning style than those in the Satisfactory group. The moderation analysis was to identify the interaction effect of learning styles on the relationship between students' profile and learning achievement. There are two types of significant enhancement moderators for this study. The universal enhancement moderator is an effective moderator for all students, while the specific enhancement moderator is recommended for specific groups. For example, sensing and neutral of Understand is the universal moderator for enhancing the student's knowledge, and reflective and sensing is the universal moderator for enhancing the programming skills. The analysis provides many insightful recommendations for lecturers to make a style-fit teaching strategy.

Future research may give a focus on the behavior monitoring module. Once this module is activated, lecturers will realize how much the students are engaging themselves in learning. The student's learning behavior will help to fulfill the analysis in the association evaluation module and lead to continual adaptive learning guidelines.

\section{References}

[1] C. Watson and F. W. B. Li, "Failure rates in introductory programming revisited," in Proceedings of the 2014 conference on Innovation \& technology in computer science education, 2014, pp. 39-44.

[2] J. Bennedsen and M. E. Caspersen, "Failure rates in introductory programming," ACM SIGcSE Bull., vol. 39, no. 2, pp. 32-36, 2007.

[3] G. Bain and I. Barnes, "Why is programming so hard to learn?," in Proceedings of the 2014 conference on Innovation \& technology in computer science education, 2014, p. 356. 
[4] M. Guzdial, "Why is it so hard to learn to program," Mak. Softw. What Really Work. Why We Believe It. O'Reilly Media, pp. 111-124, 2010.

[5] C. Romero and S. Ventura, "Data mining in education," Wiley Interdiscip. Rev. Data Min. Knowl. Discov., vol. 3, no. 1, pp. 12-27, 2013.

[6] D. Perera, J. Kay, I. Koprinska, K. Yacef, and O. R. Zaïane, "Clustering and sequential pattern mining of online collaborative learning data," IEEE Trans. Knowl. Data Eng., vol. 21, no. 6, pp. 759-772, 2008.

[7] C.-M. Chen, M.-C. Chen, and Y.-L. Li, "Mining key formative assessment rules based on learner profiles for web-based learning systems," in Seventh IEEE International Conference on Advanced Learning Technologies (ICALT 2007), 2007, pp. 584-588.

[8] Y. Psaromiligkos, M. Orfanidou, C. Kytagias, and E. Zafiri, "Mining $\log$ data for the analysis of learners' behaviour in web-based learning management systems," Oper. Res., vol. 11, no. 2, pp. 187-200, 2011.

[9] N. B. A. Normadhi, L. Shuib, H. N. M. Nasir, A. Bimba, N. Idris, and V. Balakrishnan, "Identification of personal traits in adaptive learning environment: Systematic literature review," Comput. Educ., vol. 130, pp. 168-190, 2019.

[10] S. Sfenrianto, Y. B. Hartarto, H. Akbar, M. Mukhtar, E. Efriadi, and M. Wahyudi, "An adaptive learning system based on knowledge level for English learning," Int. J. Emerg. Technol. Learn., vol. 13, no. 12, pp. 191-200, 2018.

[11] T.-C. Yang, G.-J. Hwang, and S. J.-H. Yang, "Development of an adaptive learning system with multiple perspectives based on students' learning styles and cognitive styles," J. Educ. Technol. Soc., vol. 16, no. 4, pp. 185-200, 2013.

[12] S. Bergin and R. Reilly, "Programming: factors that influence success," in ACM SIGCSE Bulletin, 2005, vol. 37, no. 1, pp. 411-415.

[13] S. G. A. van Herpen, M. Meeuwisse, W. H. A. Hofman, S. E. Severiens, and L. R. Arends, "Early predictors of first-year academic success at university: pre-university effort, pre-university self-efficacy, and preuniversity reasons for attending university," Educ. Res. Eval., vol. 23, no. 1-2, pp. 52-72, Feb. 2017.

[14] U. Ninrutsirikun, B. Watanapa, C. Arpnikanondt, and N. Phothikit, "Effect of the Multiple Intelligences in multiclass predictive model of computer programming course achievement," in IEEE Region 10 Annual International Conference, Proceedings/TENCON, 2017. 
[15] B. C. Wilson and S. Shrock, "Contributing to success in an introductory computer science course: a study of twelve factors," in ACM SIGCSE Bulletin, 2001, vol. 33, no. 1, pp. 184-188.

[16] P. Byrne and G. Lyons, "The effect of student attributes on success in programming," in ACM SIGCSE Bulletin, 2001, vol. 33, no. 3, pp. 4952.

[17] K. Davis, J. Christodoulou, S. Seider, and H. E. Gardner, "The theory of multiple intelligences," 2011.

[18] T. D. Ford, "Barriers to Computer Programming Student Success: A Quantitative Study of Community College Students in Southwest Missouri." Lindenwood University, 2015.

[19] A. Adorjan and I. F. de Kereki, "Multiple Intelligence approach and competencies applied to Computer Science 1," in 2013 IEEE Frontiers in Education Conference (FIE), 2013, pp. 1170-1172.

[20] U. Ninrutsirikun, H. Imai, B. Watanapa, and C. Arpnikanondt, "Principal Component Clustered Factors for Determining Study Performance in Computer Programming Class," Wirel. Pers. Commun., pp. 1-20, 2020.

[21] T. Gnambs, "What makes a computer wiz? Linking personality traits and programming aptitude," J. Res. Pers., vol. 58, pp. 31-34, 2015.

[22] Z. Karimi, A. Baraani-Dastjerdi, N. Ghasem-Aghaee, and S. Wagner, "Using personality traits to understand the influence of personality on computer programming: An empirical study," J. Cases Inf. Technol., vol. 18, no. 1, pp. 28-48, 2016.

[23] P. Honey and A. Mumford, Learning styles questionnaire. Organization Design and Development, Incorporated, 1989.

[24] M. Schneider and F. Preckel, "Variables associated with achievement in higher education: A systematic review of meta-analyses.," Psychol. Bull., vol. 143, no. 6, p. 565, 2017.

[25] A. E. Poropat, "A meta-analysis of the five-factor model of personality and academic performance.," Psychol. Bull., vol. 135, no. 2, p. 322, 2009.

[26] M. C. O'Connor and S. V Paunonen, "Big Five personality predictors of post-secondary academic performance," Pers. Individ. Dif., vol. 43, no. 5, pp. 971-990, 2007.

[27] M. R. Lavery, P. Acharya, S. A. Sivo, and L. Xu, "Number of predictors and multicollinearity: What are their effects on error and bias in regression?," Commun. Stat. Comput., vol. 48, no. 1, pp. 27-38, 2019. 
[28] S. K. Pinto, R. Mansfield, M. Jacobs, and D. Rubin, "Predictive model augmentation by variable transformation." Google Patents, 01-Jun2010.

[29] S. Oxman, W. Wong, and D. V. X. Innovations, "White paper: Adaptive learning systems," Integr. Educ. Solut., pp. 6-7, 2014.

[30] E. Popescu, "Diagnosing students' learning style in an educational hypermedia system," in Cognitive and emotional processes in Webbased education: Integrating human factors and personalization, IGI Global, 2009, pp. 187-208.

[31] S. Ouf, M. A. Ellatif, S. E. Salama, and Y. Helmy, "A proposed paradigm for smart learning environment based on semantic web," Comput. Human Behav., vol. 72, pp. 796-818, 2017.

[32] Y. Akbulut and C. S. Cardak, "Adaptive educational hypermedia accommodating learning styles: A content analysis of publications from 2000 to 2011," Comput. Educ., vol. 58, no. 2, pp. 835-842, 2012.

[33] M. Yilmaz-Soylu and B. Akkoyunlu, "The Effect of Learning Styles on Achievement in Different Learning Environments.," Turkish Online J. Educ. Technol., vol. 8, no. 4, pp. 43-50, 2009.

[34] H. Pashler, M. McDaniel, D. Rohrer, and R. Bjork, "Learning styles: Concepts and evidence," Psychol. Sci. public Interes., vol. 9, no. 3, pp. 105-119, 2008.

[35] R. M. Felder and L. K. Silverman, "Learning and teaching styles in engineering education,” Eng. Educ., vol. 78, no. 7, pp. 674-681, 1988.

[36] D. A. Kolb, The Kolb learning style inventory. Hay Resources Direct Boston, MA, 2007.

[37] M. Ehrman and R. Oxford, "Adult language learning styles and strategies in an intensive training setting," Mod. Lang. J., vol. 74, no. 3, pp. 311-327, 1990.

[38] R. Dunn, "Understanding the Dunn and Dunn learning styles model and the need for individual diagnosis and prescription," Reading, Writing, Learn. Disabil., vol. 6, no. 3, pp. 223-247, 1990.

[39] R. M. Felder and R. Brent, "Understanding student differences," J. Eng. Educ., vol. 94, no. 1, pp. 57-72, 2005.

[40] B. A. Soloman and R. M. Felder, "Index of learning styles questionnaire," NC State Univ. Available online http//www. engr. ncsu. edu/learningstyles/ilsweb. html (last Visit. 14.05. 2010), vol. 70, 2005.

[41] J. Allert, "Learning style and factors contributing to success in an introductory computer science course," in IEEE International 
Conference on Advanced Learning Technologies, 2004. Proceedings., 2004, pp. 385-389.

[42] A. T. Chamillard and D. Karolick, "Using learning style data in an introductory computer science course," in The proceedings of the thirtieth SIGCSE technical symposium on Computer science education, 1999, pp. 291-295.

[43] A. Gomes and A. J. Mendes, "Learning to program-difficulties and solutions," in International Conference on Engineering Education-ICEE, 2007, vol. 2007.

[44] L. Thomas, M. Ratcliffe, J. Woodbury, and E. Jarman, "Learning styles and performance in the introductory programming sequence," $A C M$ SIGCSE Bull., vol. 34, no. 1, pp. 33-37, 2002.

[45] H. M. Truong, "Integrating learning styles and adaptive e-learning system: Current developments, problems and opportunities," Comput. Human Behav., vol. 55, pp. 1185-1193, 2016.

[46] H. Fasihuddin, G. Skinner, and R. Athauda, "A Framework to Personalise Open Learning Environments by Adapting to Learning Styles.," in CSEDU (1), 2015, pp. 296-305.

[47] G. E. Evans and M. G. Simkin, "What best predicts computer proficiency?," Commun. ACM, vol. 32, no. 11, pp. 1322-1327, 1989.

[48] S. Bergin and R. Reilly, "The influence of motivation and comfort-level on learning to program," 2005.

[49] E. Chandra and K. Nandhini, "Knowledge mining from student data," Eur. J. Sci. Res., vol. 47, no. 1, pp. 156-163, 2010.

[50] V. Kumar et al., "An Approach to Measure Coding Competency Evolution," in Smart Learning Environments, Springer, 2015, pp. 27-43.

[51] G. R. Bergersen, J. E. Hannay, D. I. K. Sjøberg, T. Dyba, and A. Karahasanovic, "Inferring skill from tests of programming performance: Combining time and quality," in 2011 International Symposium on Empirical Software Engineering and Measurement, 2011, pp. 305-314.

[52] J. P. Campbell, R. A. McCloy, S. H. Oppler, and C. E. Sager, "A theory of performance: In N. Schmitt \& WC Borman (Eds.), Personnel Selection in Organizations (pp. 35-70).” San Francisco: Jossey-Bass, 1993.

[53] G. P. Latham and C. C. Pinder, "Work motivation theory and research at the dawn of the twenty-first century," Annu. Rev. Psychol., vol. 56, pp. 485-516, 2005.

[54] C.-P. Lai and J.-R. Lu, "Evaluating the efficiency of currency portfolios constructed by the mining association rules," Asia Pacific Manag. Rev., vol. 24, no. 1, pp. 11-20, 2019. 
[55] R. Agrawal, T. Imieliñski, and A. Swami, "Mining association rules between sets of items in large databases," in Acm sigmod record, 1993, vol. 22, no. 2, pp. 207-216.

[56] K. Becker, C. G. Ghedini, and E. L. Terra, "Using KDD to analyze the impact of curriculum revisions in a Brazilian university," in Data Mining and Knowledge Discovery: Theory, Tools, and Technology II, 2000, vol. 4057, pp. 412-419.

[57] N. Selmoune and Z. Alimazighi, "A decisional tool for quality improvement in higher education," in 2008 3rd International Conference on Information and Communication Technologies: From Theory to Applications, 2008, pp. 1-6.

[58] L. Zhang, X. Liu, and X. Liu, "Personalized instructing recommendation system based on web mining," in 2008 The 9th International Conference for Young Computer Scientists, 2008, pp. 2517-2521.

[59] H. Ba-Omar, I. Petrounias, and F. Anwar, "A framework for using web usage mining to personalise e-learning," in Seventh IEEE International Conference on Advanced Learning Technologies (ICALT 2007), 2007, pp. 937-938.

[60] C. Romero, A. Zafra, J. M. Luna, and S. Ventura, "Association rule mining using genetic programming to provide feedback to instructors from multiple-choice quiz data," Expert Syst., vol. 30, no. 2, pp. 162-172, 2013.

[61] O. R. Zaíane, "Building a recommender agent for e-learning systems," in International Conference on Computers in Education, 2002. Proceedings., 2002, pp. 55-59.

[62] J. Lu, "A personalized e-learning material recommender system," in International Conference on Information Technology and Applications, 2004.

[63] E. García, C. Romero, S. Ventura, and T. Calders, "Drawbacks and solutions of applying association rule mining in learning management systems," in Proceedings of the International Workshop on Applying Data Mining in e-Learning (ADML 2007), Crete, Greece, 2007, pp. 13-22.

[64] A. Merceron and K. Yacef, "Interestingness measures for association rules in educational data," in Educational Data Mining 2008, 2008.

[65] A. F. Hayes, Introduction to mediation, moderation, and conditional process analysis: A regression-based approach. Guilford Publications, 2017. 
[66] W. F. Chaplin, "The next generation of moderator research in personality psychology," J. Pers., vol. 59, no. 2, pp. 143-178, 1991.

[67] A. F. Hayes, "PROCESS: A versatile computational tool for observed variable mediation, moderation, and conditional process modeling." University of Kansas, KS, 2012.

[68] J. Wakefield and J. K. Frawley, 'How does students' general academic achievement moderate the implications of social networking on specific levels of learning performance?," Comput. Educ., vol. 144, p. 103694, 2020.

[69] D. R. Sanchez, M. Langer, and R. Kaur, "Gamification in the classroom: Examining the impact of gamified quizzes on student learning," Comput. Educ., vol. 144, p. 103666, 2020.

[70] E. R. Fyfe and B. Rittle-Johnson, "Feedback both helps and hinders learning: The causal role of prior knowledge.," J. Educ. Psychol., vol. 108, no. 1, p. 82, 2016.

[71] E. R. Fyfe, B. Rittle-Johnson, and M. S. DeCaro, "The effects of feedback during exploratory mathematics problem solving: Prior knowledge matters.," J. Educ. Psychol., vol. 104, no. 4, p. 1094, 2012.

[72] S. Timmers, M. Valcke, K. De Mil, and W. R. G. Baeyens, "The impact of computer supported collaborative learning on internship outcomes of pharmacy students," Interact. Learn. Environ., vol. 16, no. 2, pp. 131$141,2008$.

[73] C.-C. LINa, Y.-T. WUb, and T.-Y. CHENG, "Online knowledgestructure-based adaptive science learning: Integrates adaptive dynamic assessment into adaptive learning."

[74] M. K. Khribi, M. Jemni, and O. Nasraoui, "Automatic recommendations for e-learning personalization based on web usage mining techniques and information retrieval," in 2008 Eighth IEEE International Conference on Advanced Learning Technologies, 2008, pp. 241-245.

[75] M. S. Ibrahim and M. Hamada, "Adaptive learning framework," in 2016 15th International Conference on Information Technology Based Higher Education and Training (ITHET), 2016, pp. 1-5.

[76] B. Vesin, M. Ivanović, A. KlašNja-MilićEvić, and Z. Budimac, "Protus 2.0: Ontology-based semantic recommendation in programming tutoring system," Expert Syst. Appl., vol. 39, no. 15, pp. 12229-12246, 2012.

[77] B. Vesin, M. Ivanović, A. Klašnja-Milićević, and Z. Budimac, "Ontology-based architecture with recommendation strategy in java 
tutoring system," Comput. Sci. Inf. Syst., vol. 10, no. 1, pp. 237-261, 2013.

[78] O. Conlan, V. Wade, C. Bruen, and M. Gargan, "Multi-model, metadata driven approach to adaptive hypermedia services for personalized elearning," in International Conference on Adaptive Hypermedia and Adaptive Web-Based Systems, 2002, pp. 100-111.

[79] U. Ninrutsirikun, B. Watanapa, C. Arpnikanondt, and V. Watananukoon, "A Unified Framework for Student Cluster Grouping with Learning Preference Associative Detection for Enhancing Students' Learning Outcomes in Computer Programming Courses," in 2018 Global Wireless Summit (GWS), 2018, pp. 266-271.

[80] B. Mark, Theory of Knowledge: Structures and Processes, vol. 5. World scientific, 2016.

[81] I. Katsov, Introduction to Algorithmic Marketing: Artificial Intelligence for Marketing Operations. Ilia Katcov, 2017.

[82] R. L. Ebel, "Marks and marking systems," IEEE Trans. Educ., vol. 17, no. 2, pp. 76-92, 1974.

[83] O. P. John and S. Srivastava, "The Big Five trait taxonomy: History, measurement, and theoretical perspectives," Handb. Personal. Theory Res., vol. 2, no. 1999, pp. 102-138, 1999.

[84] G. James, D. Witten, T. Hastie, and R. Tibshirani, An introduction to statistical learning, vol. 112. Springer, 2013.

[85] V. Fonti and E. Belitser, "Feature selection using lasso," VU Amsterdam Res. Pap. Bus. Anal., 2017.

[86] M. I. Lopez, J. M. Luna, C. Romero, and S. Ventura, "Classification via clustering for predicting final marks based on student participation in forums.," Int. Educ. Data Min. Soc., 2012.

[87] Y. S. Koh and N. Rountree, "Rare Association Rule Mining: An Overview," in Rare Association Rule Mining and Knowledge Discovery: Technologies for Infrequent and Critical Event Detection, IGI Global, 2010, pp. 1-14.

[88] R. M. Felder and J. Spurlin, "Applications, reliability and validity of the index of learning styles," Int. J. Eng. Educ., vol. 21, no. 1, pp. 103-112, 2005.

[89] R. M. Felder and B. A. Soloman, "Learning styles and strategies." 2000.

[90] I. A. Zualkernan, J. Allert, and G. Z. Qadah, "Learning styles of computer programming students: a Middle Eastern and American comparison," IEEE Trans. Educ., vol. 49, no. 4, pp. 443-450, 2006. 
[91] M. M. Quinn, T. Smith, E. L. Kalmar, and J. M. Burgoon, "What type of learner are your students? Preferred learning styles of undergraduate gross anatomy students according to the index of learning styles questionnaire," Anat. Sci. Educ., vol. 11, no. 4, pp. 358-365, 2018.

\section{Biographies}

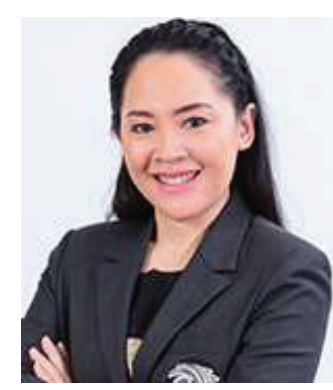

Unhawa Ninrutsirikun is a lecturer at School of Information Technology, King Mongkut's University of Technology Thonburi Bangkok, Thailand. She will receive her Ph.D. in Information Technology from SIT, KMUTT, Thailand in 2021. Her research interests are in Computer and Education, Data Analysis, and Machine Learning.

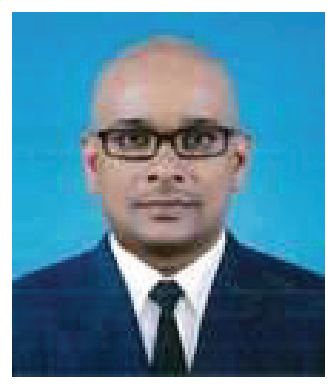

Debajyoti Pal is a researcher at School of Information Technology, King Mongkut's University of Technology Thonburi Bangkok, Thailand. He received his Ph.D. in Information Technology from KMUTT in 2017. His research interests are in Quality evaluation of multimedia-services, IoT security and Human computer interaction. 


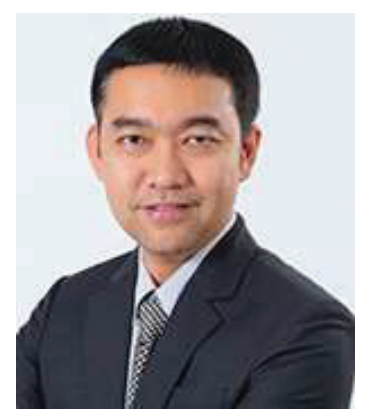

Chonlameth Arpnikanondt received his Ph.D. degree from Georgia Tech in the US. He is currently an Assistant Professor in the School of Information Technology at KMUTT, Thailand. His research work has been in the application areas of systems and software design and modeling. His current research interests include mobile digital health, mobile-based digital transformation and usability.

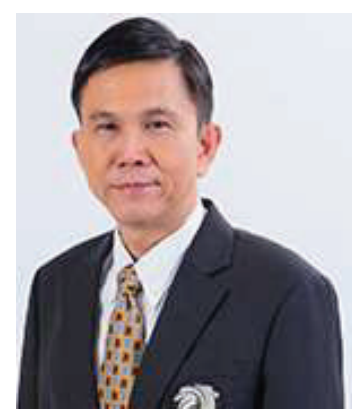

Bunthit Watanapa is an associate professor at School of InformationTechnology, King Mongkut's University of Technology Thonburi Bangkok, Thailand. He has completed his D.Eng. in Industrial Engineering in 2004 from Asian Institute of Technology, Thailand. His research interests are in Artificial Neural Networks and Data Mining. 